\title{
LOW CYCLE FATIGUE OF NiAl DEFORMED NEAR THE
}

\author{
BRITTLE-TO-DUCTILE TRANSITION TEMPERATURE
}

\author{
Cheryl L. Cullers and Stephen D. Antolovich \\ School of Materials Engineering \\ Mechanical Properties Research Laboratory \\ Georgia Institute of Technology
}

\begin{abstract}
As part of a study to investigate the fatigue behavior of the intermetallic compound $\mathrm{NiAl}$ near its monotonic brittle-to-ductile transition temperature (BDTT), prealloyed stoichiometric NiAl powders were hot extruded and fabricated into tensile and fatigue specimens. From the monotonic tests conducted at a nominal strain rate of $10^{-4} \mathrm{sec}^{-1}$, the BDTT was found to be approximately $650 \mathrm{~K}$. Low cycle fatigue (LCF) tests were performed at 600,675 , and $700 \mathrm{~K}$ at plastic strain ranges of 0.005 and 0.01 . The percentage of intergranular failure decreased in the fracture morphology of both the monotonic and fatigue tests. For all temperatures and strain ranges in this study, rapid hardening was observed for up-to 15 cycles, after which the peak stress increased only slightly for the remainder of the life. As test temperature was increased or strain range decreased, both the initial hardening rate and relative saturation stress decreased. Additionally, slip traces were observed on the gage surfaces of all LCF specimens. In fatigue specimens, secondary cracks were found in the gage section near the eventual fracture site. Transgranular surface cracks apparently resulted from slip intrusions/extrusions. Intergranular surface cracks were seen that could result from planar slip pile-ups at grain boundaries, however other mechanisms have not been ruled out. No significant improvement in life at a strain range of 0.005 was observed when the test temperature was increased from 600 to $700 \mathrm{~K}$, a change which corresponds to an increase in monotonic tensile ductility from 2 to $18 \%$. Apparently, a cyclic brittle-to-ductile transition did not occur in this temperature range. If thermally activated deformation affects fatigue lives as it does monotonic ductility, the cyclic transition temperature is higher than the monotonic BDTT. More work is necessary to precisely identify the deformation mechanisms that operate in low cycle fatigue of NiAl.
\end{abstract}

Superalloys 1992

Edited by S.D. Antolovich, R.W. Stusrud, R.A. MacKay,

D.L. Anton, T. Khan, R.D. Kissinger, D.L. Klarstrom

The Minerals, Metals \& Materials Society, 1992 


\section{Introduction}

$\mathrm{NiAl}$ is under intense investigation as a potential alternative to conventional superalloys due to its excellent oxidation resistance, low density, and high melting temperature. Despite these advantages, NiAl exhibits poor high-temperature strength and low ambienttemperature ductility and fracture toughness. In polycrystalline form, and in most single crystal orientations, NiAl deformation occurs on $\{110\}$ planes along $<001>$ directions. Motion of $<001>$ dislocations provides only three of the five slip systems necessary for generalized plasticity [1]. The resulting strain incompatibility at grain boundaries results in intergranular cracking at temperatures below the brittle-to-ductile transition temperature (BDTT) after as little as $2 \%$ plastic strain [2]. When NiAl is deformed in compression at temperatures below the BDTT, macroscopic deformation can be obtained because there is little driving force for crack propagation. However, when tested in tension, the presence of the grain boundary cracks, combined with the poor fracture toughness of NiAl below the BDTT, provides a strong crack driving force and leads to intergranular failure at very low levels of tensile plastic strain. Improvements in alloy cleanliness and processing control have resulted in numerous reports of room temperature tensile ductilities of $1-2 \%$ [3-5]. Above about $600 \mathrm{~K}$, tensile ductility increases markedly and the percentage of transgranular fracture increases [6]. Several studies [1,2,6-10] have suggested that thermally activated deformation processes, possibly dislocation climb, provide the additional deformation mechanisms necessary to eliminate grain boundary cracking and result in the sharp transition from brittle to ductile behavior.

Although many investigations have explored monotonic deformation of $\mathrm{NiAl}$, very few fatigue studies have been reported. Hartfield-Wünsch [11,12] performed room temperature cyclic deformation on $\mathrm{Ni}_{49} \mathrm{Al}_{31} \mathrm{Fe}_{20}$ (which, like NiAl, deforms along <001> slip directions) at plastic strain ranges between 0.0004 and 0.01 and total strain rates between $3.4 \times 10^{-5}$ and $10^{-4} \mathrm{sec}^{-1}$. The $\mathrm{Ni}_{49} \mathrm{Al}_{31} \mathrm{Fe}_{20}$ fractured in a predominately transgranular manner, experienced cyclic softening followed by hardening, and displayed little or no asymmetry between tensile and compressive stress amplitudes. Bain et. al. [13] reported on the cyclic behavior of $<001>$ single crystal NiAl-0.1\% Mo at room temperature and $1033 \mathrm{~K}$. Secondary cracks, which coalesced and caused fast fracture, were observed parallel to the loading axis. The $1033 \mathrm{~K}$ cyclic lives were longer than René N4 at high total strain ranges due to the larger ductility of NiAl. However at low total strain ranges, the NiAl crystals had shorter lives since the low yield strength of $\mathrm{NiAl}$ led to plastic deformation at strain ranges where René N4 remained elastic. Lerch and Noebe have performed room temperature [14] and $1000 \mathrm{~K}$ [15] cyclic fatigue tests on polycrystalline $\mathrm{NiAl}$ at plastic strain ranges between 0.0006 and 0.002 at a total strain rate of $10^{-3} \mathrm{sec}^{-1}$. The polycrystalline NiAl work hardened continuously at room temperature and failed in a predominately intergranular fashion. Their room temperature study found that in strain controlled fatigue NiAl had longer lives than other ordered B2 compounds. It is also interesting to note that the lives reported by Bain [13] at $1033 \mathrm{~K}$ and Lerch and Noebe [15] at $1000 \mathrm{~K}$ were similar. The purpose of the present study was to further investigate basic deformation process in NiAl by conducting plastic strain controlled fatigue tests on stoichiometric $\mathrm{NiAl}$ at temperatures near the monotonic BDTT.

\section{$\underline{\text { Experimental Procedures }}$}

A near stoichiometric NiAl billet was prepared by hot extrusion of vacuum atomized, prealloyed powders. The chemistry of the extrusion product is given in Table I. Optical 
Table I - Composition (atomic percent)

\begin{tabular}{clllll}
\hline $\mathrm{Ni}^{*}$ & $\mathrm{Al}^{*}$ & $\mathrm{C}$ & $\mathrm{O}_{2}$ & $\mathrm{~S}$ & $\mathrm{~N}_{2}$ \\
50.48 & 49.46 & 0.014 & 0.02 & $<0.003$ & $<0.001$ \\
\hline
\end{tabular}

*determined by wet chemical analysis, \pm 0.2 atomic percent within a $95 \%$ confidence interval

metallography revealed that the extruded material had a recrystallized, equiaxed grain structure with an average linear intercept grain size of $39 \mu \mathrm{m}$. Blanks for cylindrical, button-head, tension and fatigue specimens were electro-discharge machined from the extrusion and ground parallel to the extrusion axis. The tensile specimens had approximately $30 \mathrm{~mm}$ long and $3 \mathrm{~mm}$ diameter gage sections. The gage sections for the fatigue specimens were approximately $15 \mathrm{~mm}$ long with a $4 \mathrm{~mm}$ diameter. The gage sections were electropolished in a methanol-10\% perchloric acid solution at $205 \mathrm{~K}$ prior to testing to eliminate surface flaws that could lead to premature failure. Tensile specimens were tested in a screw-driven test frame at a constant cross-head speed corresponding to a nominal strain rate of $10^{-4} \mathrm{sec}^{-1}$. Load versus time data were recorded and converted to true stress and true strain values by assuming constant volume during plastic deformation. Elevated temperature tensile tests were performed at 300, 600, 650, and $700 \mathrm{~K}$ using a resistance furnace.

Fully reversed, total strain-rate controlled, low cycle fatigue (LCF) tests were conducted on a computer controlled, servo-hydraulic test frame. LCF tests were run at constant plastic strain ranges of 0.005 and 0.01 at a total strain rate of $10^{-4} \mathrm{sec}^{-1}$. Strain measurements were made using a $12.7 \mathrm{~mm}$ strain-gage extensometer with alumina blade extensions. Plastic strain was calculated continuously by subtracting the elastic portion from the total strain. Temperatures for the fatigue tests were chosen based on the monotonic test results and achieved using a $2 \mathrm{KW}$ induction furnace. The maximum temperature gradient in the gage section during fatigue testing was $10 \mathrm{~K}$ and the average gage temperature was within $\pm 5 \mathrm{~K}$ of the desired temperature. A single fatigue geometry specimen was tested in tension to failure at $600 \mathrm{~K}$ to verify consistency between the two testing procedures.

Fracture surfaces were examined in a Hitachi S-800 scanning electron microscope (SEM). Transmission electron microscopy (TEM) was conducted on a JOEL $100 \mathrm{CX}$ at accelerating voltages of 100 and $150 \mathrm{KeV}$. TEM foils were prepared by thinning in a solution of $70 \%$ ethanol, $13.7 \%$ water, $10 \%$ butyl cellosolve, and $6.3 \%$ perchloric acid at approximately $268 \mathrm{~K}$ and 0.2 amps.

\section{$\underline{\text { Results }}$}

Monotonic true stress-strain curves for the NiAl alloy used in this study are shown in Figure 1. Before converting the tensile load-time data to stress-strain, the spring constant, $\mathrm{k}$, was calculated for the test frame and the displacement from the frame was subtracted from the tensile data. At room temperature the specimen failed elastically and no yield stress was observed. However, past research has shown the tensile failure stress at ambient temperature to approximately equal the compressive yield stress [9,2] and no significant differences in tensile and compressive yicld stress for stoichiometric NiAl have been demonstrated in other studies [16]. Thus the room temperature yield stress was on 
the order of the fracture stress, or $155 \mathrm{MPa}$, and decreased to $141 \mathrm{MPa}$ at $700 \mathrm{~K}$. The fracture stress, on the other hand, increased from 155 to $374 \mathrm{MPa}$ between room temperature and $700 \mathrm{~K}$. As the test temperature increased, the fracture morphology became more predominately transgranular. The shape of the plastic strain to failure versus temperature curve closely resembled those of other BDTT curves determined for nominally stoichiometric NiAl extrusions $[10,6,2]$. The tensile BDTT, commonly defined as the lowest temperature for which $5 \%$ plastic strain is achieved, for this extrusion was approximately $650 \mathrm{~K}$. From these monotonic results, fatigue test temperatures were chosen $(600,675,700 \mathrm{~K})$ such that deformation would be examined slightly above and below the BDTT. The tensile ductilities corresponding to the temperatures of interest were approximately $2 \%, 7 \%$, and $18 \%$ for 600,675 , and $700 \mathrm{~K}$, respectively.

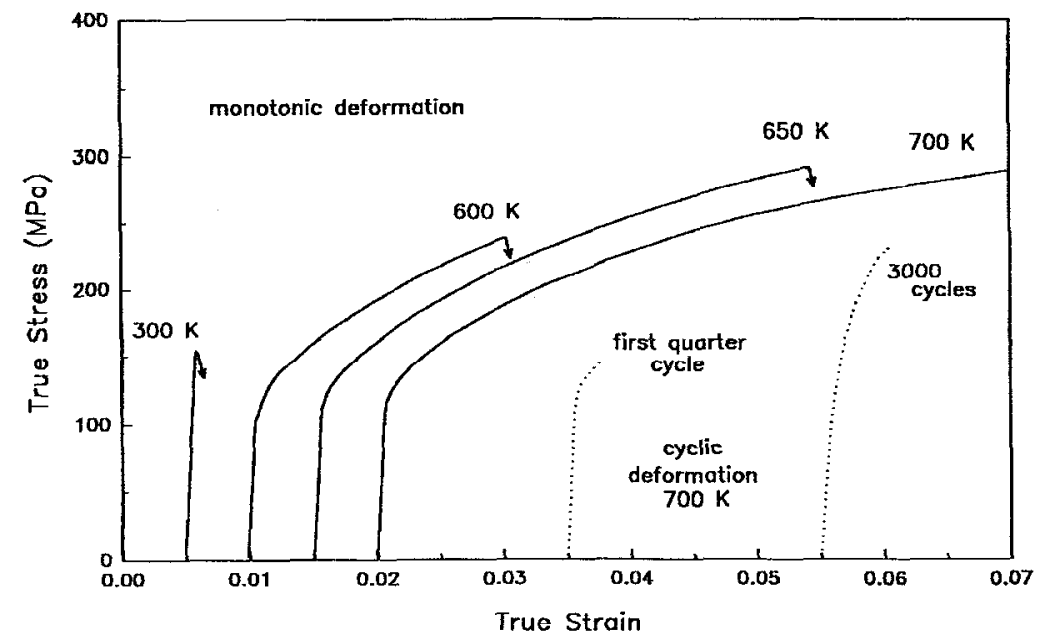

Figure 1 - True stress versus strain for monotonic and cyclic tests, $\dot{e}_{t}=10^{-4} \mathrm{~s}^{-1}$. Dotted lines are the tensile portion of loops for fatigue specimen at $700 \mathrm{~K}, \Delta \epsilon_{\mathrm{p}}=0.005$.

Figure 2 shows typical stress-strain hysteresis loops at various stages of life for cyclically deformed $\mathrm{NiAl}$. The width of the loops remained essentially constant indicating accurate strain control. The total strain in each loop increased as the peak tensile and compressive stress increased. The slope upon initial reversal/unloading did not change during the course of the fatigue tests. A difference in tensile and compressive stress amplitudes was not apparent for most fatigue test conditions. At the lowest temperature and highest strain range, however, there was a difference between stress amplitudes with the absolute value of compressive stress being up-to $10 \mathrm{MPa}$ higher than the tensile stress amplitude. This small decrease in tensile stress amplitude was probably indicative of an increasing amount of cracking.

Tensile stress amplitude versus cumulative plastic strain, Figure 3(a-b), for fatigue specimens show that at all three temperatures and both strain rates hardening occurred for the first few (up to 15) cycles followed by nearly stable behavior. Cyclic softening was not observed in any of the test conditions. Although similar in character, as tcst temperature was increased the rate of initial hardening decreased, the accumulated deformation necessary for relative saturation decreased, and the stabilized stress decreased. A similar shift in fatigue response was seen when the temperature was held constant and plastic strain range was decreased from 0.01 to 0.005 . The only significant decrease in fatigue life occurred at $600 \mathrm{~K}$ and $\Delta \epsilon_{\mathrm{p}}=0.01$ where duplicate tests could not 
produce lives past 10 cycles. However, at this temperature the alloy had only $2 \%$ tensile ductility and the test probably reflected tensile behavior more than fatigue behavior.

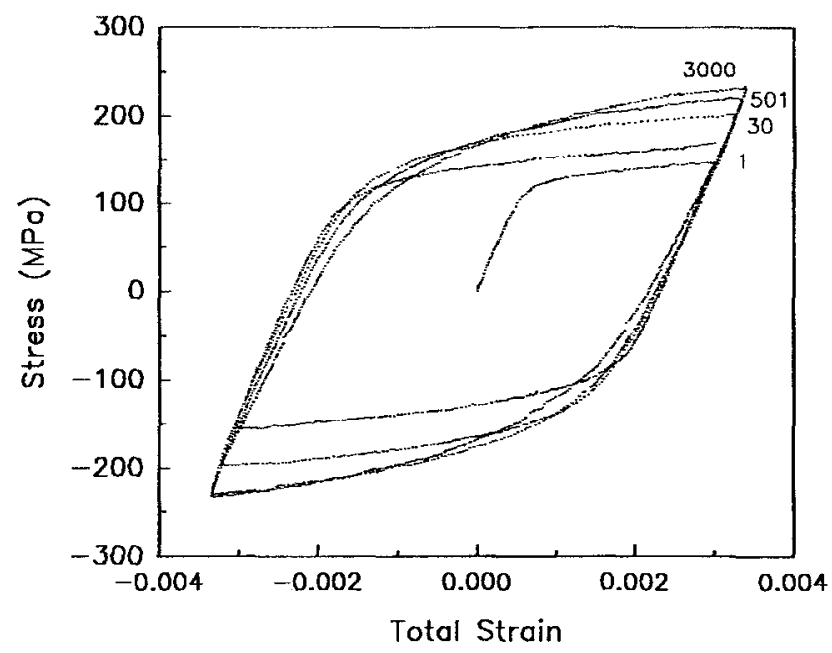

Figure 2 - Hysteresis loops 1, 30, 501, \& 3000 showing gradual hardening for a specimen tested at $700 \mathrm{~K}, \Delta \epsilon_{\mathrm{p}}=0.5 \%$, and $\dot{\mathrm{e}}_{\mathrm{t}}=10^{-4} \mathrm{~s}^{-1}$.

SEM observations of fatigue specimens revealed that failures initiated near the surface or at internal flaws. All failures occurred within the gage section, except one which failed near the radius due to a large inclusion. SEM examination of the fracture surfaces, Figure 4, revealed the fracture morphology to be both intergranular fracture and transgranular cleavage. An estimate of the area fraction of intergranular fracture, obtained by point counting, revealed the percentage decreased from $47.0 \%( \pm 6.2)$ at $600 \mathrm{~K}$ to $32.5 \%( \pm 3.6)$ at $700 \mathrm{~K}$, following the same trends as monotonic failures. Transgranular cleavage facets were distinctly more prevalent near the initiation site. There were, however, no clear demarcations separating regions of cyclic crack growth and fast fracture. There also were no observable indications of oxidation occurring at these test temperatures. Intergranular cracking was also evident on gage sections near the fracture surfaces. Correlations between the amount of secondary intergranular cracking and test conditions are being investigated.
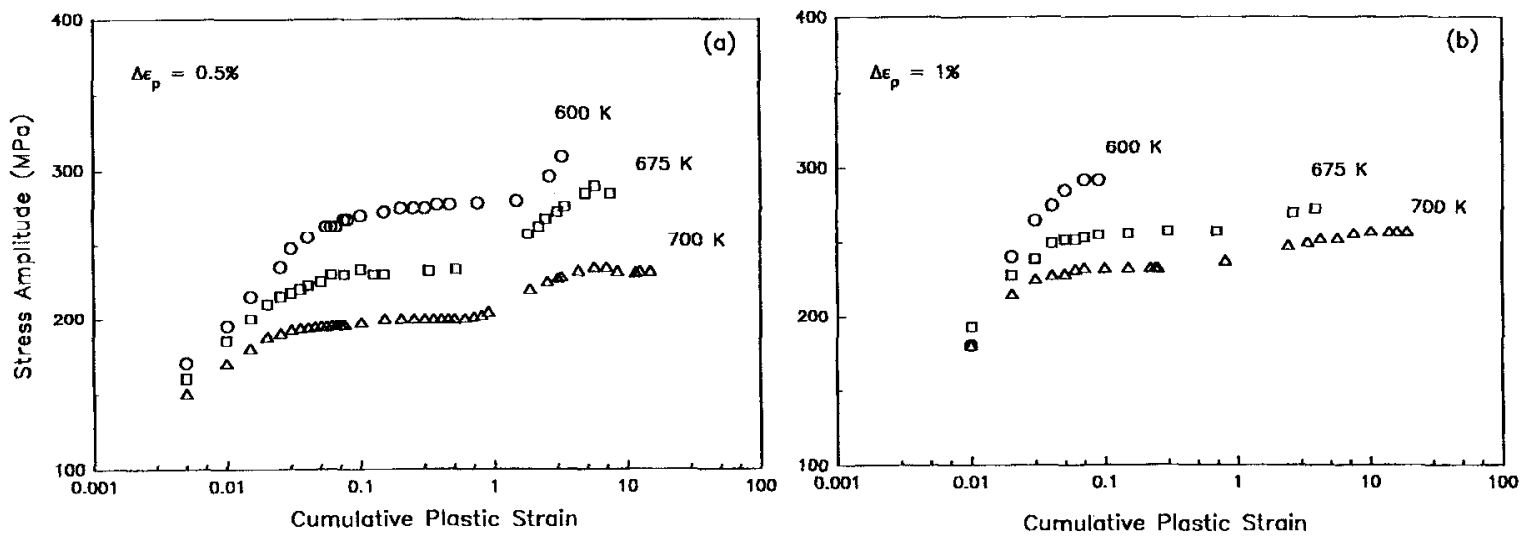

Figure 3 - Stress amplitude versus cumulative plastic strain as a function of temperature for $\mathrm{NiAl}$ tested at $\dot{\mathrm{e}}_{\mathrm{t}}=10^{-4} \mathrm{~s}^{-1}$; (a) $\Delta \epsilon_{\mathrm{p}}=0.5 \%$ and (b) $\Delta \epsilon_{\mathrm{p}}=1.0 \%$. 
Slip band traces were observed by SEM on the gage surface of all the failed fatigue tests. Figure 5 is a SEM micrograph of slip traces near the fracture surface of a specimen tested at $700 \mathrm{~K}$ and $\Delta \epsilon_{\mathrm{p}}=0.01$ showing regions of very fine regularly spaced slip lines and macroscopic intrusion/extrusion lines with less regular spacing. In many cases, slip lines were obvious initiation sites for secondary cracks either intergranularly at the slip trace/grain boundary intersections, region a in Figure 5, or transgranularly at the intrusion/extrusion boundary, region b. While the slip traces were not limited to the area immediately adjacent to the fracture site, the density was highest near the location of final fracture. Also, the slip line density was greater in specimens tested at lower temperatures and higher strain ranges. Preliminary results indicate that even though specimens tested at 600 and $700 \mathrm{~K}$, Figure 3(a), had similar amounts of cumulative strain at failure, the slip lines were less dense at $700 \mathrm{~K}$. Figure 6 is a TEM micrograph of the same specimen shown in both Figures 4 and 5 . The bands seen in Figure 6 are about $1.5 \mu \mathrm{m}$ apart. This spacing corresponds to bands with a spacing approximately equal to that of the very fine slip lines seen in Figure 5.

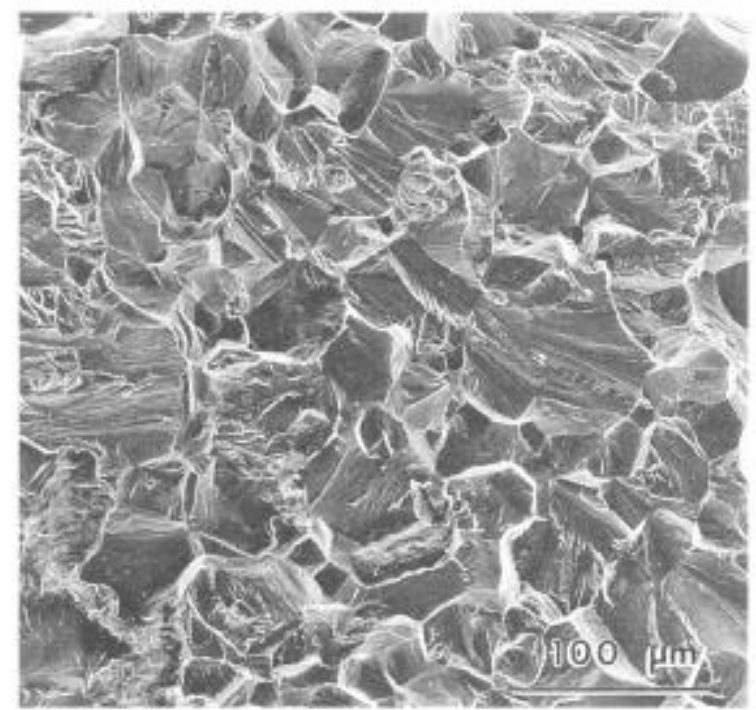

Figure 4 - SEM micrograph showing the mixed-mode nature of a fatigue fracture surfaces tested at $700 \mathrm{~K}$ and $\Delta \epsilon_{\mathrm{p}}=1.0 \%$. Intergranular fracture is $32.5 \%$.

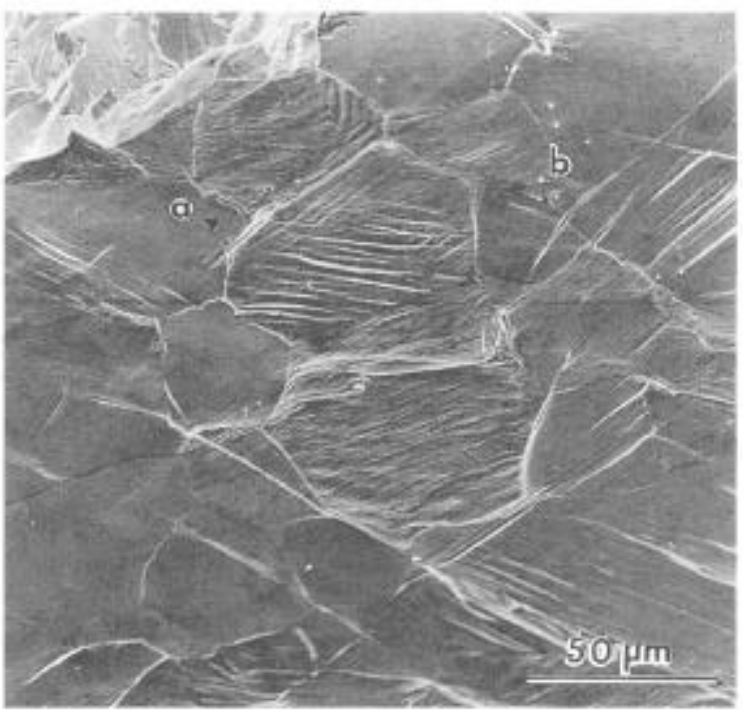

Figure 5 - SEM micrograph of the gage of same specimen shown in Figure 4. Cracks are pointed out (a) intergranularly and (b) at a slip intrusion/extrusion.

\section{Discussion}

Based on known changes in monotonic behavior, the similarity between $\mathrm{NiAl}$ fatigue behavior at 600 and $700 \mathrm{~K}$ was an unexpected result. In the monotonic tests, intergranular fracture was significantly reduced at temperatures above the BDTT. The percentage of intergranular failure on the fatigue fracture surfaces likewise decreased, however, grain boundary cracking still occurred at temperatures where generalized plasticity was believed to eliminate grain boundary cracking in monotonic deformation. The monotonic tensile fracture stress and ductility increased greatly over this temperature range, yet the fatigue response showed only a gradual decrease in relative saturation stress and a slight increase in life. As shown in Figure 3(a), the cumulative behavior was very comparable at 600 and $700 \mathrm{~K}$ and, in fact, closely resembled the hardening to failure response observed at room 
temperature [14]. Although the purpose of this study was not to generate life data, the relatively small change in life between 600 and $700 \mathrm{~K}$ at $\Delta \epsilon_{\mathrm{p}}=0.005$ was very striking. At $1000 \mathrm{~K}$ however, Lerch and Noebe observed considerable ductility and increased fatigue life over room temperature tests [15], indicating a transition in fatigue deformation occurs at some point.

The intergranular cracks seen on the side of the fatigue specimens at temperatures above the BDTT might have resulted from any one, or a combination, of several factors. Above the BDTT during monotonic deformation, thermally activated processes provide the additional deformation mechanisms to relieve strain incompatibility at the grain boundaries $[1,2,6-10]$. Conceivably, the dislocation climb thought to allow generalized deformation at grain boundaries could be hindered or prevented in cyclic deformation. However, the decrease in intergranular failure in the fatigue fracture morphology, paralleling the change in monotonic fracture morphology, suggests that grain boundary strain relief still occurs. Rather than being caused by the lack of generalized deformation, intergranular cracks in fatigue specimens could be the result of slip traces piling up at grain boundaries. Alternatively, high temperature intergranular cracking could be the result of additional damage due to oxidation at grain boundaries or other cyclic deformation mechanisms. Fatigue tests are being conducted at temperatures higher than $700 \mathrm{~K}$ to determine whether or not a sharp transition in cyclic behavior exists and occurs higher than its monotonic counterpart. Metallographic cross sections of tested specimens are being studied to determine if intergranular cracking is a surface phenomenon or occurs throughout the cross section.

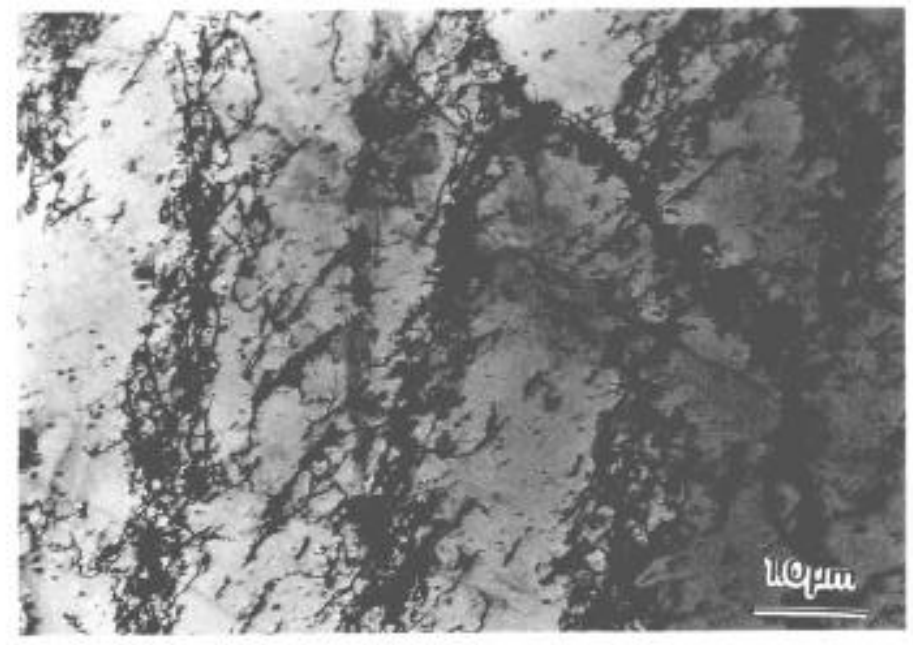

Figure 6 - TEM micrograph of a fatigue specimen tested at $700 \mathrm{~K}$ and $\epsilon_{\mathrm{p}}=1.0 \%$ showing slip bands, with a spacing of $1.5 \mu \mathrm{m}$, which correspond to the fine slip lines seen in Figure 5.

The slip traces observed during SEM examination of the gage surfaces indicated that planar deformation occurred during the fatigue of NiAl. The distance between the very fine, regularly spaced slip lines seen on specimen gages corresponds well with the band spacing measured in preliminary TEM studies. The slip lines intersecting the specimen surface were directly contributing to secondary cracking. Cracks were seen opening at slip traces, probably the result of surface intrusions and extrusions. As mentioned above, intergranular cracks were seen adjacent to slip lines. The slip lines established by cyclic deformation may develop cracks that are of critical flaw size without being sensitive to the 
relief of enhanced ductility through the generalized deformation provided by thermal activation.

\section{Conclusions}

There are at least two possible explanations for the limited change in fatigue response in the intermediate temperature range, $600-700 \mathrm{~K}$. If thermally activated processes control the fatigue behavior of NiAl, the cyclic BDTT appears to be higher than the monotonic BDTT. However, the expected decrease in the percentage of intergranular fracture yet continuing prominence of intergranular secondary cracks suggests that generalized plasticity is not the governing effect. These results strongly suggest that the cyclic lives are controlled by the presence of cracks which are independent of the generalized deformation provided by thermal activation. As noted in the introduction, the $1000 \mathrm{~K}$ lives for single crystal $\mathrm{NiAl}$ are almost identical to the lives of the polycrystalline material. The similarity between lives suggests that slip incompatibility at grain boundaries is not the dominant factor in polycrystalline material. The critical fatigue flaws are likely cracks developed as the result of slip intrusion/extrusions, slip trace pile-ups at grain boundaries or a mechanism not yet identified such as grain boundary oxidation. More work is required to complete the characterization of basic deformation mechanisms under cyclic conditions and to understand the interactions of thermal processes, slip mode, and fatigue response. A full understanding of the behavior of $\mathrm{NiAl}$ in cyclic loading is necessary before $\mathrm{Ni \Lambda l}$ can be used in high temperature, structural applications. Future tests will be performed at higher temperatures to more fully examine the role of thermally activated processes and their role in controlling deformation. More extensive TEM of interrupted tests will be used to explore the extent of planar deformation and to look for the presence of other mechanisms.

\section{Acknowledgments}

This work was supported by NASA Lewis Research Center under Grant NCC3-116 and the helpful supervision of M. V. Nathal. The authors would like to thank R. R. Bowman, B. A. Lerch, and R. D. Noebe for their insightful discussions and their review of the manuscript.

\section{References}

1. A. Ball and R. E. Smallman, "The Operative Slip System and General Plasticity of NiAl-II," Acta Metall., 14 (1966), 1517-1426.

2. R. R. Bowman et al., "Correlation of Deformation Mechanisms with the Tensile and Compressive Behavior of $\mathrm{NiAl}$ and $\mathrm{NiAl}(\mathrm{Zr})$ Intermetallic Alloys," Metall. Trans., 23A (1992), 1493-1508.

3. A. G. Rozner and R. J. Wasilewski, "Tensile Properties of NiAl and NiTi," J. Inst. Metals, 94 (1966), 169-175.

4. K. Vedula, K. H. Hahn, and B. Boulogne, "Room Temperature Tensile Ductility in Polycrystalline B2 NiAl," High Temperature Ordered Intermetallic Alloys III (Pittsburgh, PA: Mater. Res. Soc. Symp. Proc. vol. 133, 1989), 299-304.

5. E. P. Gcorge and C. T. Liu, "Brittle Fracture and Grain Boundary Chemistry of Microalloyed NiAl," J. Mater. Res., 5 (1990), 754-762. 
6. R. D. Noebe, C. L. Cullers, and R. R. Bowman, "The Effect of Strain Rate and Temperature on the Tensile Properties of NiAl," J. Mater. Res., 7 (1992), 605-612.

7. A. Ball and R. E. Smallman, "The Deformation Properties and Electron Microscopy of the Intermetallic Compound NiAl," Acta Metall., 14 (1966), 13491355.

8. H. L. Fraser, M. H. I oretto, and R. E. Smallman, "The Plastic Deformation of NiAl Single Crystals between $300 \mathrm{~K}$ and $1050 \mathrm{~K}$ II. The Mechanism of Kinking and Uniform Deformation," Phil. Mag., 28 (1973), 667-677.

9. R. D. Noebe et. al., "Flow and Fracture Behavior of NiAl with Prospects for Future Alloy Development," HITEMP Review-1990, NASA CP-10051 (1990), 20-1.

10. R. D. Noebe et. al., "Flow and Fracture Behavior of NiAl in Relation to the Brittle-to-Ductile Transition Temperature," High Temperature Ordered Intermetallic Alloys IV (Pittsburgh, PA: Mater. Res. Soc. Symp. Proc. vol. 213, 1991), 589-596.

11. S. E. Hartfield-Wünsch and R. Gibala, "Cyclic Deformation of B2 Aluminides," High Temperature Ordered Intermetallic Alloys IV (Pittsburgh, PA: Mater. Res. Soc. Symp. Proc vol. 213, 1991), 575-580.

12. S. E. IIartfield-Wünsch, "Monotonic and Cyclic Deformation Behavior of B2 Aluminides" (Ph.D. thesis, Univ. of Michigan, 1991), 106-116.

13. K. R. Bain, R. D. Field, and D. F. Lahrman, "Fatigue Behavior of NiAl Single Crystals" (Paper presented at the Fall TMS Meeting, Cincinnati, OH 1991).

14. R. D. Noebe and B. A. Lerch, "Room Temperature Cyclic Deformation Behavior of Cast and Extruded NiAl" (Submitted to Scipta Metall. Mater., 1992).

15. B. A. Lerch and R. D. Noebe, unpublished research, NASA Lewis Research Center, 1992.

16. R. D. Noebe, R. R. Bowman, and M. V. Nathal, "Review of the Physical and Mechanical Properties of the B2 Compound NiAl" (Submitted to International Materials Review, 1992). 